Maxime O. Baud, MD,

$\mathrm{PhD}$

Jeffrey R. Vitt, MD

Nathaniel M. Robbins, MD

Rafael Wabl, MD

Michael R. Wilson, MD, MAS

Felicia C. Chow, MD, MAS

Jeffrey M. Gelfand, MD, MAS

S. Andrew Josephson, MD

Steve Miller, MD, PhD

Correspondence to

Dr. Miller:

steve.miller@ucsf.edu

Supplemental data at http://links.Iww.com/ NXI/A3

\title{
Pleocytosis is not fully responsible for low CSF glucose in meningitis
}

OPEN

\section{ABSTRACT}

Objective: The mechanism of hypoglycorrhachia-low CSF glucose-in meningitis remains unknown. We sought to evaluate the relative contribution of CSF inflammation vs microorganisms (bacteria and fungi) in lowering CSF glucose levels.

Methods: We retrospectively categorized CSF profiles into microbial and aseptic meningitis and analyzed CSF leukocyte count, glucose, and protein concentrations. We assessed the relationship between these markers using multivariate and stratified linear regression analysis for initial and repeated CSF sampling. We also calculated the receiver operating characteristics of CSF glucose and CSF-to-serum glucose ratios to presumptively diagnose microbial meningitis.

Results: We found that increasing levels of CSF inflammation were associated with decreased CSF glucose levels in the microbial but not aseptic category. Moreover, elevated CSF protein levels correlated more strongly than the leukocyte count with low CSF glucose levels on initial $\left(R^{2}=36 \%, p<0.001\right)$ and repeated CSF sampling $\left(R^{2}=46 \%, p<0.001\right)$. Hypoglycorrhachia $(<40 \mathrm{mg} / \mathrm{dL}$ ) was observed in $50.1 \%$ of microbial cases, but only $9.6 \%$ of aseptic cases, most of which were neurosarcoidosis. Absolute CSF glucose and CSF-to-serum glucose ratios had similar low sensitivity and moderate-to-high specificity in diagnosing microbial meningitis at thresholds commonly used.

Conclusions: The main driver of hypoglycorrhachia appears to be a combination of microbial meningitis with moderate to high degrees of CSF inflammation and proteins, suggesting that the presence of microorganisms capable of catabolizing glucose is a determinant of hypoglycorrhachia in meningitis. A major notable exception is neurosarcoidosis. Low CSF glucose and CSF-to-serum glucose ratios are useful markers for the diagnosis of microbial meningitis. Neurol Neuroimmunol Neuroinflamm 2018;5:e425; doi: 10.1212/NXI.0000000000000425

\section{GLOSSARY}

ROC $=$ receiver operating characteristics.

Hypoglycorrhachia-low CSF glucose-has been recognized since the $1930 \mathrm{~s}^{1,2}$ as a critical clinical laboratory finding with the potential to influence treatment of meningitis and is therefore reported within 1 hour by most laboratories. Marked hypoglycorrhachia has traditionally been viewed as a predictor of microbial meningitis (caused by bacteria, mycobacteria, fungi, and parasites, but not viruses) in both adults and children ${ }^{3-5}$ and heralds poor outcomes including death. ${ }^{6-9}$ The differential diagnosis for hypoglycorrhachia includes not only microbial but also neoplastic causes as well as select primary inflammatory meningitides such as neurosarcoidosis. ${ }^{10-12}$ While neoplastic meningitis can usually be suspected when it presents in the context of a known malignancy, ${ }^{13}$ microbial and aseptic etiologies (viral, chemical, and autoimmune) can be difficult to distinguish on clinical grounds alone. To date, and more than a hundred years after the first observations, hypoglycorrhachia remains an important CSF marker for etiologic

From the Department of Neurology (M.O.B., J.R.V., N.M.R., M.R.W., F.C.C., J.M.G., S.A.J.) and Department of Laboratory Medicine (S.M.), University of California, San Francisco; and Department of Neurology (R.W.), University of Michigan, Ann Arbor. N.M.R. is currently affiliated with the Department of Neurology, Dartmouth Geisel School of Medicine.

Funding information and disclosures are provided at the end of the article. Go to Neurology.org/nn for full disclosure forms. The Article Processing Charge was funded by the authors.

This is an open access article distributed under the terms of the Creative Commons Attribution-NonCommercial-NoDerivatives License 4.0 (CC BY-NC-ND), which permits downloading and sharing the work provided it is properly cited. The work cannot be changed in any way or used commercially without permission from the journal. 
diagnosis, as serology, microbiology, and cytology have low sensitivity and can take days until results are available. Finding the etiology is key, as immediate initiation of the correct targeted treatment against specific pathogens improves prognosis. ${ }^{14}$

Despite intense experimental meningitis research in the 1960s, the pathophysiology underlying CSF glucose depletion remains controversial. Because hypoglycorrhachia is associated with higher degrees of CSF inflammation, ${ }^{15}$ it has long been debated whether inflammation or microbial load is most responsible for depleting CSF glucose. Commonly cited mechanisms include increased glucose catabolism by leukocytes, microorganisms, or the brain parenchyma, as well as altered glucose transport across inflamed meninges. ${ }^{10,16,17}$ The introduction of bacteria in cisternal CSF decreased glucose within a few hours, arguing in favor of direct microbial catabolism, ${ }^{18}$ but the effect was not confirmed in leukopenic dogs, suggesting that the host inflammatory response is also necessary to cause hypoglycorrhachia. ${ }^{17}$ Induction of chemical meningitis did not alter CSF glucose, showing that inflammation alone may not be sufficient and suggesting the presence of a synergy with microbial metabolism. ${ }^{17}$ Finally, the uptake of radiolabeled glucose was increased in neutrophils derived from purulent CSF, showing that they contribute to glucose depletion. ${ }^{19}$ To our knowledge, these experimental results have never been correlated with large human clinical data sets, despite recent advances in the understanding of immune mechanisms at play in meningitis.

The aim of this cross-sectional study was to evaluate the relative contribution of CSF inflammation vs microbial infection in driving hypoglycorrhachia in the clinical context of microbial and aseptic meningitis. We made the hypothesis that because all leukocytes (neutrophils, lymphocytes, or monocytes) have the capability of catabolizing glucose, they could be a major determinant of hypoglycorrhachia, including in aseptic meningitis. We retrospectively collected meningitis CSF profiles-defined as the presence of pleocytosis-with confirmed microbial and aseptic etiologies. This dichotomization offered a natural experiment to compare CSF glucose levels along a continuum of varying degrees of CNS inflammation in the presence (microbial) or the absence (aseptic) of microorganisms capable of catabolizing glucose across a broad range of meningitis etiologies.

METHODS Samples. We included 225 inflammatory CSF (pleocytosis $\geq 6 \times 10^{6} \mathrm{cell} / \mathrm{L}$ ) obtained by lumbar puncture at the time of clinical presentation into the main analysis and 83 additional repeat samples belonging to the same patients (cutoff: 7 days to 1 month) into the longitudinal analyses (supplemental information and figure e-1, http://links.lww.com/NXI/A3). The University of California, San Francisco Institutional Review Board approved the study protocol and granted a waiver of informed consent for retrospective chart review with no patient contact.

Variables. Absolute CSF glucose $(\mathrm{mg} / \mathrm{dL}, \mathrm{n}=225)$ and CSF-toserum glucose ratios (abbreviated glucose ratio, with a cutoff for serum glucose within 12 hours of CSF, $\mathrm{n}=156,69.0 \%$ and $67.0 \%$ of the microbial and aseptic cases, respectively) were tabulated alongside CSF protein, CSF cell count and differential (missing for 13), and serum leukocyte count (obtained within 24 hours of CSF sampling), age at presentation, sex, HIV and diabetes status, and whether the meningitis was immediately (postoperative) or remotely (shunt infections) associated with neurosurgery. In the case of CSF samples with a high number of red blood cells, we reviewed the chart to check whether the lumbar puncture was traumatic and accordingly selected data coming from the last tube collected (aseptic, $\mathrm{n}=9$ and microbial, $\mathrm{n}=8$ ). We dichotomized the diagnoses into 2 groups: microbial and aseptic meningitis (supplemental information for details, http://links.lww.com/NXI/A3). All statistical analyses were performed on the entire database on absolute CSF glucose and repeated for the subset of patients on the glucose ratio to ensure congruent results.

Statistical analysis. First, we obtained univariate linear regressions of CSF inflammation markers onto CSF glucose. The distribution of CSF glucose and glucose ratios was tested for normality. The CSF leukocyte count and protein were log transformed before further analysis, as their distribution was inversely exponential. To test for independence of these predictors, we used a stepwise multivariate linear regression approach seeking global optimization of the corrected $R^{2}$. For fitting, we used a bisquare method to increase robustness to outliers. We initialized the model including all predictors significant at the univariate level and included all interaction terms between hypothesized predictors (diagnostic category and CSF leukocyte count) and effect modifiers (CSF protein) but left out interactions with potential confounders. In a stepwise approach, we then discarded variables that were not independent, starting with potential confounders. The final fit yielded the following model: $G=\beta_{0}+\beta_{1} D M+\beta_{2} D x+\beta_{3} D x \times \log P+\varepsilon$, where $G$ is the dependent variable CSF glucose, and the explanatory variables are $D M$ for diabetes mellitus (categorical, 1 for present), $D x$ for diagnostic category (categorical, 1 for microbial), and $P$ for CSF protein (continuous). All other terms were not independent predictors, including the leukocyte count. Given the significant interaction term between 2 predictors (diagnostic category and CSF protein), a stratified post hoc $t$ test (Bonferroni corrected, $p<0.017$ ) was conducted using a 3-level variable for protein concentration: low (50-100 mg/dL), medium (101-180 mg/dL), 
and high (181-500 mg/dL). Note that the neutrophil count was not an independent predictor in the multivariate model, but because it can often distinguish between microbial and aseptic meningitis, we also repeated the stratified analysis with the absolute CSF neutrophil count categorized as low $\left(>20 \times 10^{6} / \mathrm{L}\right)$ and high $\left(>50 \times 10^{6} / \mathrm{L}\right)$. Sensitivity analyses of the multivariate model included exclusion of neurosurgical cases, analyzing only surgical cases, exclusion of culture-negative cases, analyzing inflammatory and infectious aseptic meningitis cases separately, and stratifying by neutrophil count.

Second, to add longitudinal information on individual patients and assess the validity of following CSF glucose as a marker for response to treatment, we checked whether a linear relationship between $\log P$ and $G$ was conserved over time. For each repeat CSF sample obtained between 1 week and 1 month of the initial CSF sample ( $\mathrm{n}=83$ samples in 52 patients), we plotted the change in glucose $(\operatorname{delta} G)$ vs the change in $\log P$ compared with its corresponding initial CSF sample: $\operatorname{delta} G=\beta_{0}+\beta_{1}\left(\log P_{2}-\log P_{1}\right)+\varepsilon$. Third, to complement analysis of the average trend (linear regression) with an analysis of the extremes and to quantify the performance of CSF glucose and the glucose ratio in diagnosing microbial meningitis, we performed a receiver operating characteristics (ROC) analysis. True-positive rate $\left(\frac{\sum \text { true positive }}{\sum \text { true positive }+\sum \text { false negative }}\right)$ and false-positive rate $\left(\frac{\sum \text { false positive }}{\sum \text { false positive }+\sum \text { true negative }}\right)$ were calculated for detection thresholds on CSF glucose or the glucose ratio incrementing in 100 linear steps over the full range of values. All values are

\begin{tabular}{|c|c|c|c|}
\hline \multirow[t]{2}{*}{ Univariate analysis } & s for aseptic and micr & obial meningitis & \multirow[b]{2}{*}{ p Value } \\
\hline & Aseptic & Microbial & \\
\hline $\mathrm{N}$ & 115 & 110 & \\
\hline Age, y & $41.0 \pm 17.6$ & $44.5 \pm 20.5$ & NS \\
\hline Children $<16$ y old & $8(7.0 \%)$ & $9(8.2 \%)$ & NS \\
\hline Male-to-female (ratio) & 0.85 & 1.97 & $<0.01^{b}$ \\
\hline HIV & 7 (6.1\%) & $16(14.5 \%)$ & $0.04^{b}$ \\
\hline Diabetes mellitus & $13(11.3 \%)$ & $13(11.8 \%)$ & $N S^{b}$ \\
\hline Remote neurosurgery & $2(1.7 \%)$ & 12 (10.9\%) & $<0.01^{\mathrm{b}}$ \\
\hline Recent neurosurgery & 1 (0.9\%) & 21 (19.1\%) & $<0.001^{b}$ \\
\hline White blood cell count, $10^{9}$ cells $/ \mathrm{L}$ & $9.0 \pm 4.1(n=92)$ & $11.4 \pm 6.5(n=88)$ & $<0.01^{\mathrm{b}}$ \\
\hline Traumatic CSF sampling & 9 & 8 & $N S^{b}$ \\
\hline CSF glucose, mg/dL & $62.2 \pm 20.6$ & $41.1 \pm 26.7$ & $<0.001^{c}$ \\
\hline Hypoglycorrhachia $<40 \mathrm{mg} / \mathrm{dL}$ & 12 (10.4\%) & $56(50.1 \%)$ & $<0.001^{\mathrm{b}}$ \\
\hline Hypoglycorrhachia $<30 \mathrm{mg} / \mathrm{dL}$ & 2 (1.7\%) & 42 (38.2\%) & $<0.001^{b}$ \\
\hline CSF-to-serum glucose (ratio) & $0.55 \pm 0.14(n=79)$ & $0.36 \pm 0.18(n=77)$ & $<0.001^{c}$ \\
\hline Delay CSF-serum, $\mathrm{h}$ & $4.2 \pm 3.3$ & $3.6 \pm 3.6$ & NS \\
\hline CSF protein, mg/dL & $68(19-2,720)^{a}$ & $150(10-4,043)^{a}$ & $<0.001^{\mathrm{d}}$ \\
\hline CSF leukocytes, $10^{6}$ cells/L & $45(7-1850)^{a}$ & $147(6-24,400)^{\mathrm{a}}$ & $<0.001^{d}$ \\
\hline CSF lymphocytes, \% & $68.2 \pm 29.7$ & $39.0 \pm 34.5$ & $<0.001^{c}$ \\
\hline CSF monocytes, \% & $17.3 \pm 18.3$ & $11.5 \pm 8.8$ & $<0.01^{\mathrm{c}}$ \\
\hline CSF neutrophils, \% & $13.4 \pm 24.7$ & $47.7 \pm 36.2$ & $<0.001^{c}$ \\
\hline
\end{tabular}

Values expressed as counts (\%) or mean \pm SD except for ashown as median and range. $p$ Values represent the result of ${ }^{b} \chi^{2}$ test, cpaired $t$ test, or ${ }^{d}$ paired $t$ test after logarithmic transform. NS = not significant. reported as mean $\pm \mathrm{SD}$, unless otherwise specified, and significance was accepted at $p<0.05$ after Bonferroni correction.

RESULTS Patients and CSF samples. We included 115 aseptic and 110 microbial meningitis cases with similar demographics (tables 1 and 2). Both included a minority of pediatric cases ( $10.4 \%$ vs $10.9 \%$ ), with ages ranging from 2 to 88 and 5-90 years, respectively. Microbial cases were more likely to be men, to have a history of neurosurgery and to be HIV infected. As expected in the microbial category, the white blood cell count was slightly increased, average absolute CSF glucose and glucose ratios were decreased, and, conversely, CSF inflammatory markers were increased. These variables were tested as potential confounders in the model below.

Predictors of low CSF glucose. At the univariate level (table e-1, http://links.lww.com/NXI/A3), a history of diabetes mellitus, aseptic vs microbial diagnostic category, CSF protein, CSF leukocyte count, and the proportion of neutrophils vs lymphocytes correlated with absolute CSF glucose levels, as well as sex and a history of recent neurosurgery when the glucose ratio was the dependent variable. A stepwise multivariate linear regression revealed that only diabetes mellitus $\left(\beta_{1}, 20.3 \pm 4.2, p<0.001\right)$ and the interaction between CSF protein and a microbial status $\left(\beta_{3},-21.4 \pm 6.9, p<0.01\right)$ were independently and significantly related to absolute CSF glucose (degree of freedom $=218$, adjusted- $R^{2}=0.36$ ) . When using the glucose ratio as the dependent variable, the explained variance improved by approximately $10 \%$ (degree of freedom $=167$, adjusted $-R^{2}$ $=0.46)$, with diabetes mellitus $\left(\beta_{1},-0.10 \pm 0.03\right.$, $p<0.01)$, microbial status $\left(\beta_{2}, 0.35 \pm 0.12, p<0\right.$. 01 ), and the interaction between CSF protein and a microbial status $\left(\beta_{3},-0.24 \pm 0.06, p<0.001\right)$ being the only independent variables. Of note, CSF leukocytes fell out of the model, likely because it correlated with CSF protein (Pearson correlation $=0$. $49, p<0.001, \mathrm{n}=213,2$ missing values). All other predictors fell out of the model including the repartition of leukocytes. Additional sensitivity analysis showed similar results when the regression analysis was performed, excluding cases related to recent or remote neurosurgery, cases of microbial meningitis without a documented pathogen, considering inflammatory and infectious aseptic meningitis separately and when comparing similar degrees of neutrophilic pleocytosis (table e-2, http://links.lww.com/NXI/A3).

Because the model included a significant interaction term between CSF protein and diagnostic category, we followed up with a stratified analysis to achieve a better understanding of the effects of each variable separately (figure 1). First, CSF protein significantly predicted CSF glucose only in the microbial 


\begin{tabular}{|c|c|c|}
\hline Table 2 & \multicolumn{2}{|c|}{$\begin{array}{l}\text { Number of cases per etiology of meningitis (\% of total } \mathrm{N} \text { in category) ir } \\
\text { the aseptic and microbial categories }\end{array}$} \\
\hline & Aseptic & Microbial \\
\hline Viral & & Bacterial \\
\hline \multicolumn{2}{|c|}{ Varicella zoster virus: 8 (7.0\%) } & Staphylococcus: 30 (27.3\%) \\
\hline \multicolumn{2}{|c|}{ West Nile virus: 8 (7.0\%) } & Gram negative: 12 (10.9\%) \\
\hline \multicolumn{2}{|c|}{ Herpes simplex virus: 3 (2.6\%) } & Streptococcus: 9 (8.1\%) \\
\hline \multicolumn{2}{|c|}{ Epstein-Barr virus: 2 (1.7\%) } & Mycobacterium: 3 (2.7\%) \\
\hline \multicolumn{2}{|c|}{ Cytomegalovirus: 1 (0.8\%) } & Treponema: 6 (5.5\%) \\
\hline \multicolumn{2}{|c|}{ Enterovirus: $1(0.8 \%)$} & Brucella: 2 (1.8\%) \\
\hline \multicolumn{2}{|c|}{ Probable unidentified virus: 26 (22.6\%) } & Borrelia: 1 (0.9\%) \\
\hline \multicolumn{2}{|c|}{ Inflammatory } & Nocardia: 1 (0.9\%) \\
\hline \multicolumn{2}{|c|}{ Neurosarcoidosis: 25 (21.7\%) } & Probable unidentified bacteria: 15 (13.6\%) \\
\hline \multicolumn{2}{|c|}{ Neuromyelitis optica: 16 (13.9\%) } & Fungal/parasitic \\
\hline \multicolumn{2}{|c|}{ Antibody mediated: 8 (7.0\%) } & Cryptococcus: 13 (11.8\%) \\
\hline \multicolumn{2}{|c|}{ CNS angiitis: 6 (5.2\%) } & Coccidioides: 10 (9.0\%) \\
\hline \multicolumn{2}{|c|}{ ADEM: 3 (2.6\%) } & Sporothrix: 3 (2.7\%) \\
\hline \multicolumn{2}{|c|}{ Chemical: 3 (2.6\%) } & Toxoplasmosis: 2 (1.8\%) \\
\hline \multicolumn{2}{|c|}{ Neuro-Behçet: 2 (1.7\%) } & Mucor: 1 (0.9\%) \\
\hline \multicolumn{2}{|c|}{ HaNDL syndrome: 2 (1.7\%) } & Aspergillus: 1 (0.9\%) \\
\hline \multicolumn{2}{|c|}{ Vogt-Koyanagi-Harada: 1 (0.8\%) } & Histoplasma: 1 (0.9\%) \\
\hline
\end{tabular}

Abbreviations: ADEM = acute disseminated encephalomyelitis; HaNDL $=$ headache neurologic deficits with CSF lymphocytosis.

Note that the majority of cases had proven etiologic diagnosis, and a minority $(22.6 \%$ aseptic and $13.6 \%$ septic) were clinically certain based on the course of disease and response to treatment. glucose $<30 \mathrm{mg} / \mathrm{dL}$ or glucose ratio $<0.3$, reflecting the very low CSF glucose levels seen more frequently in microbial meningitis cases (table 1).

Low glucose in aseptic meningitis. Among aseptic meningitis cases $(\mathrm{n}=115)$, only 11 cases $(9.6 \%)$ had CSF glucose lower than $40 \mathrm{mg} / \mathrm{dL}$ (median 33, range $16-37 \mathrm{mg} / \mathrm{dL}$ ). Eight cases were neurosarcoidosis (half confirmed by brain and the other half by lung biopsy), a diagnosis that has been associated with hypoglycorrhachia in the literature. ${ }^{11,20}$ The remaining cases were 2 neuromyelitis optica with positive aquaporin-4 serum antibodies (one with mild hypoglycemia of $64 \mathrm{mg} / \mathrm{dL}$ and the other with correction of the hypoglycorrhachia on the next day) and 1 brain biopsy-confirmed small vessel CNS vasculitis with associated leptomeningitis. The median age was 43 years (range 28-64 years), and 9 were women. CSF inflammatory markers were moderately elevated including proteins (median 125, range 65-300 mg/dL) and leukocytes (median 58, range 9-685 $10^{6} \mathrm{cells} / \mathrm{L}$ ) with a lymphocytic predominance $(78.4 \% \pm 27.7 \%$ lymphocytes and $3.3 \% \pm 4.5 \%$ neutrophils).

DISCUSSION In this study, we showed that, contrary to our hypothesis, the presence of glucophagic microorganisms (bacteria, mycobacteria, fungus, or parasite) is the predominant determinant of hypoglycorrhachia and that depletion of CSF glucose is more pronounced in the setting of more severe infections with higher pleocytosis and proteins. In the absence of such a pathogen, a similar degree of CSF inflammation is per se, not sufficient to significantly decrease CSF glucose on average, with a few notable exceptions including cases of biopsy-confirmed neurosarcoidosis. Furthermore, the degree of pleocytosis was not an independent predictor of hypoglycorrhachia when CSF protein was taken into account, and the type of pleocytosis did not play a crucial role.

From these data, we understand that either (1) the presence of both glucophagic microorganisms and a significant degree of inflammation synergistically induce hypoglycorrhachia; or (2) CSF protein is a marker for another variable we could not measure, such as microbial load and/or function of the blood-brain barrier. Of note, CSF protein in meningitis can be of microbial (e.g., bacterial wall) or endogenous origin (e.g., immunoglobulins), which may explain its predictive strength in our model as it combines 2 variables into 1 metric. Unfortunately, microbial load is not routinely measured in CSF, so we could not test this hypothesis. Taking into account early work on animal experimental meningitis, it is conceivable that a synergy between CSF inflammatory mechanisms and the presence of glucophagic microorganisms stimulates leukocytic glucose 
A

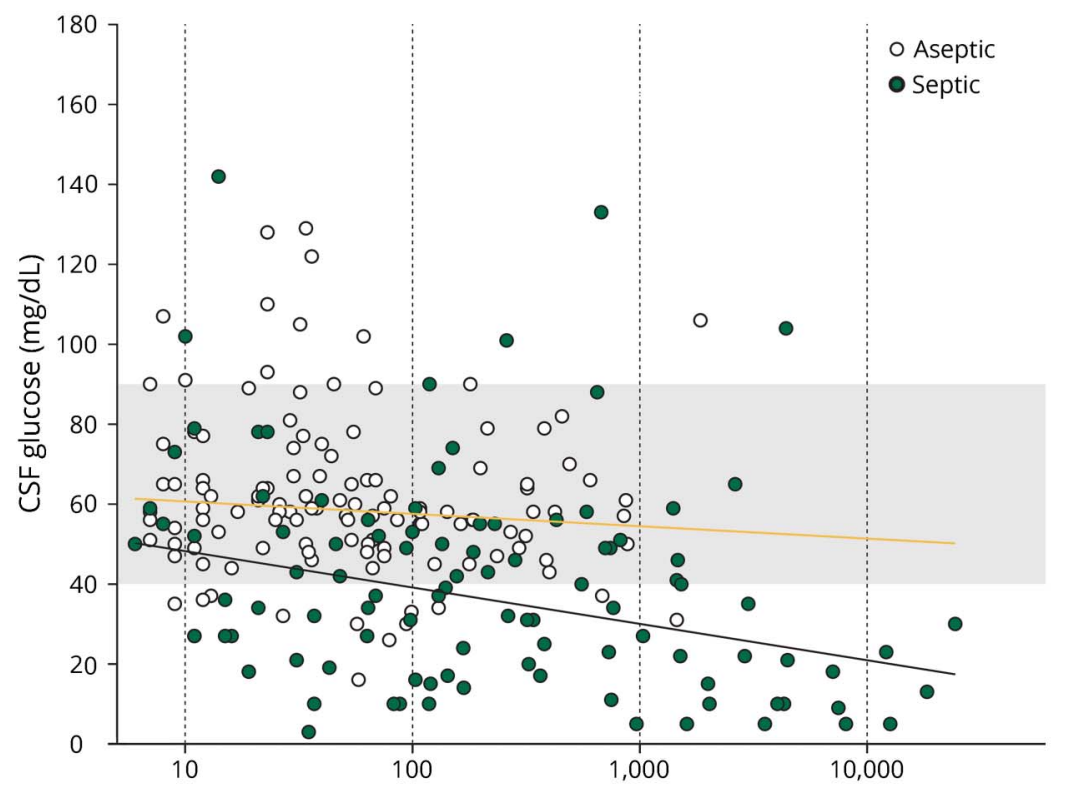

B

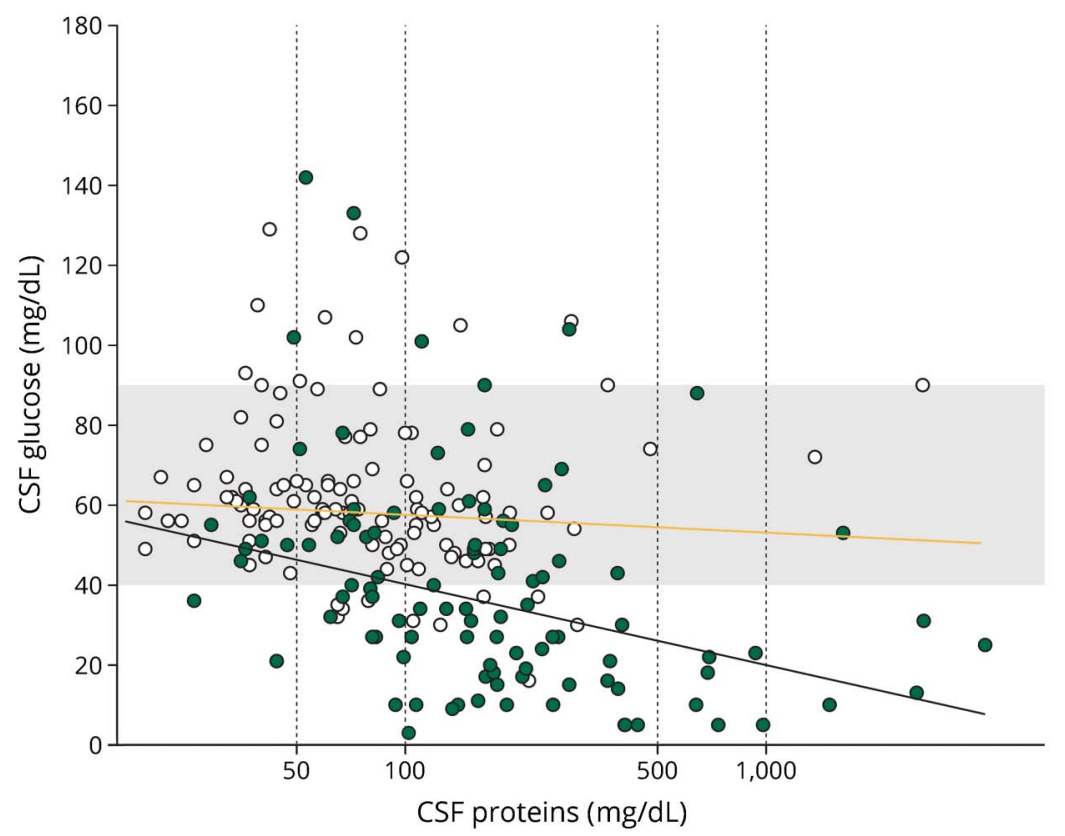

C. CSFp $50-100 \mathrm{mg} / \mathrm{dL}$

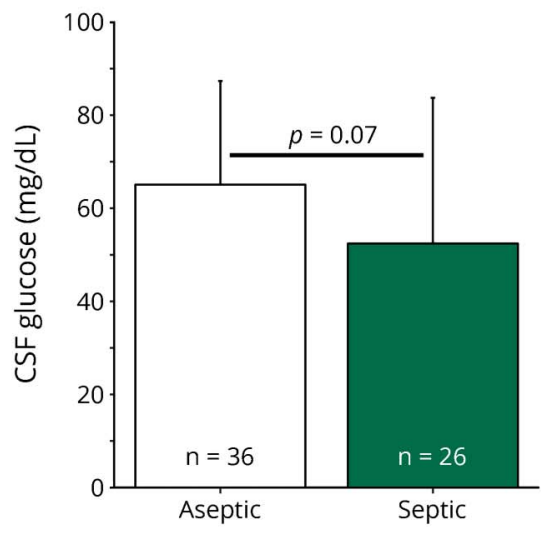

D. CSFp $101-180 \mathrm{mg} / \mathrm{dL}$

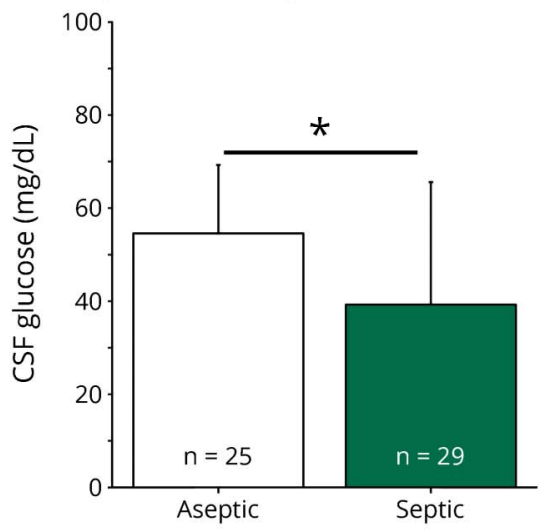

E. CSFp $181-500 \mathrm{mg} / \mathrm{dL}$

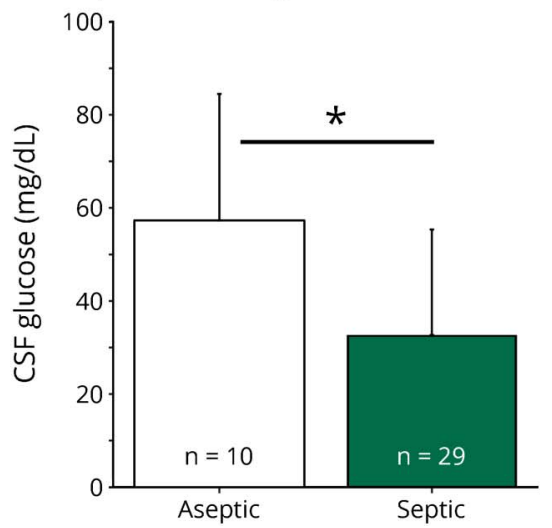

(A) Trend showing lower CSF glucose level with the higher CSF leukocyte count in the microbial category $\left(\beta=-9.1, R^{2}=13 \%, p<0.001\right.$, black line) but not in the aseptic category (yellow line, $p=0.23$ ). (B) The CSF glucose level is significantly lowered with the elevated CSF protein level in the microbial category ( $\beta=-20.2, R^{2}=17 \%, p<0.001$, black line) but not in the aseptic category (yellow line, $p=0.28$ ). (C-E) Stratified analysis of the effect of the diagnostic category on CSF glucose within similar degrees of inflammation as assessed by the protein levels, low $(p=0.07)$, intermediate $(p=0.01)$, and high $(p<0.01)$. Note that the glucose level is significantly decreased only in microbial meningitis at intermediate and high levels of CSF protein. * $p \leq 0.01$.

catabolism. ${ }^{17,19}$ Alternatively, glucose transport across the blood-brain barrier might be reduced as proposed in cases of tuberculous meningitis ${ }^{2}$ and experimental meningitis. ${ }^{16}$

Microbial and aseptic meningitis differ in their immune inflammatory responses, as illustrated by the presence of neutrophilic vs lymphocytic pleocytosis. For this reason, we also evaluated the effect of the absolute neutrophil count alone and found no difference in the interpretation of results with the caveat that relatively few samples contributed to this analysis. We also observed that all eleven outlying cases of aseptic meningitis with low CSF glucose had a lymphocytic pleocytosis, supporting the 


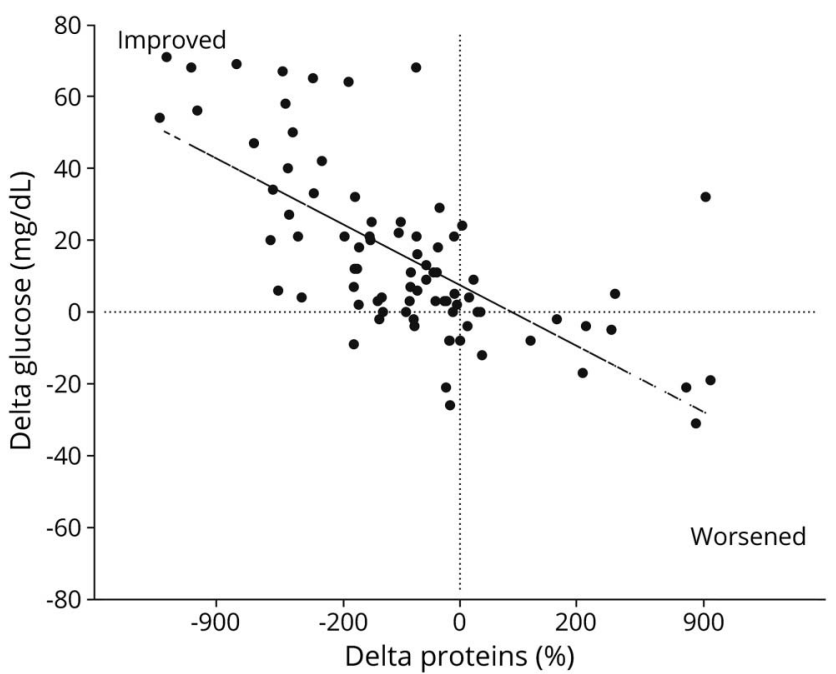

Delta glucose and changes in proteins represent the difference between a repeat CSF sample and the corresponding initial CSF sample. Note the strong linear relationship $\left(p=10^{-12}\right)$ and the fact that most data points fall either in the upper left quadrant (improvement) or in the lower right quadrant (worsening), indicating an inverse correlation between CSF glucose and protein levels.

idea that hypoglycorrhachia is independent of the leukocyte type. These cases were for the most part (8/11) biopsy-proven neurosarcoidosis, confirming previous reports. ${ }^{11,12,21}$ As exemplified by the typical granulomatous inflammation found on pathology, neurosarcoidosis resembles inflammatory responses to microbial meningitis. Little is known about the exact

\section{Figure 3 Receiver operating characteristics for CSF glucose $(n=225)$ and serum/} CSF glucose ratio $(n=156)$ as predictors for microbial meningitis

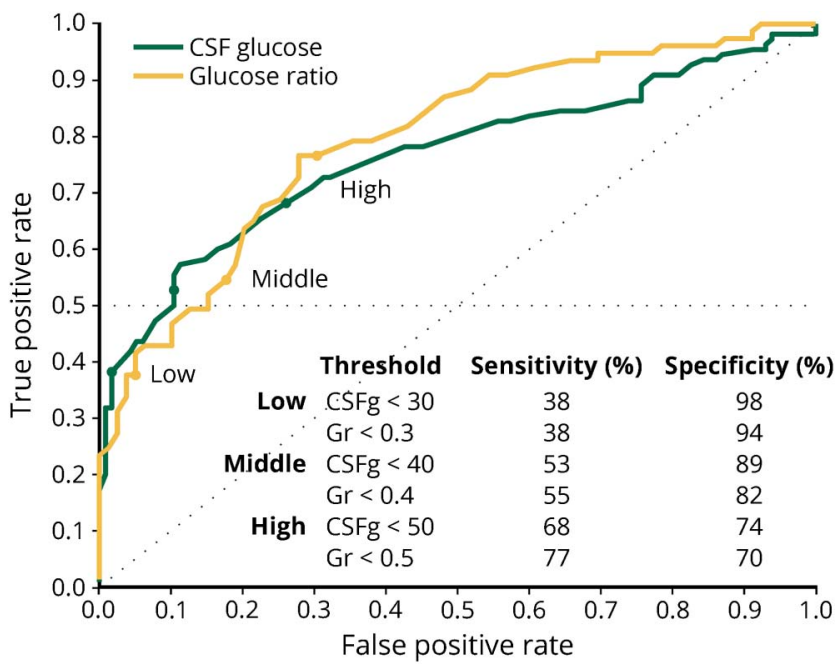

The sensitivity and specificity of different clinically meaningful threshold levels are shown in the inset table and at corresponding dots on the curves (low, middle, and high thresholds). Note that when a low threshold is chosen, the raw glucose and glucose ratio perform similarly with high specificity for microbial cases but very low sensitivity. On the other hand, when a high threshold is chosen, the glucose ratio performs approximately $10 \%$ better than raw glucose in terms of sensitivity for equivalent specificity. Thresholds typically used in clinical practice are in the middle range. CSFg $=$ CSF glucose; $\mathrm{Gr}=$ Glucose ratio. molecular pathways of neuroinflammation in neurosarcoidosis, but whole blood transcriptome analyses of patients with active pulmonary sarcoidosis resemble that of inflammatory responses to active mycobacterial infection. ${ }^{22}$ If involvement of similar inflammatory responses in the brain was confirmed, this may provide a clue for why CSF glucose can be low in neurosarcoidosis but not in other archetypical CNS inflammatory disorders. Pathway analysis, rather than cell-type analysis, might provide novel insights into mechanisms of hypoglycorrhachia in aseptic meningitis. Thus, other aspects of meningeal inflammation, which were not directly measured here, may be the common denominator in determining hypoglycorrhachia.

In the second part of this study, longitudinal analysis with repeated CSF sampling in a subset of patients with microbial meningitis revealed an inverse correlation between CSF protein and glucose concentration. This was interpreted as a marker of the response to treatment or the lack thereof. When microorganisms are effectively killed, inflammation decreases and glucose catabolism decreases as well. The strong linear relationship found here suggests that CSF glucose and CSF protein are valuable biomarkers to track the clinical progression of microbial meningitis.

Third, ROC analysis showed that both CSF raw glucose and the CSF-to-serum glucose ratio were specific but not sensitive tests to detect microbial meningitis at thresholds used in clinical practice. In our study, there was a mild benefit of using the glucose ratio (with serum levels obtained within 12 hours) instead of raw glucose to achieve higher sensitivity (approximately 10\% increase), and it therefore probably reflects a more accurate estimation of glucose repartition in the 2 compartments. ${ }^{23,24}$ For these reasons, it should be preferred over absolute CSF glucose when making clinical predictions; however, our data illustrate that it is not a widespread practice. We did not have enough time points to investigate whether the glucose ratio obtained within shorter time frames (e.g., \pm 2 hours) would yield better ROC.

The limitations of the study include its use of single-center retrospectively collected laboratory measures without the ability to further explore pathologic mechanisms or control for uniform collection of variables. In a prospective study asking the same questions, a number of additional control variables could be collected. The blood-brain barrier integrity could be assessed by parallel measurement of albumin in the plasma and CSF. Lactate quantification could clarify a potential role for anaerobic metabolism. ${ }^{16}$ Proteins could be further separated into those of microbial origin and immunoglobulins. Microbial load could be quantified using PCR, and a tight 
CSF-to-serum glucose ratio could be assessed systematically. Although promising, newer biomarkers such as serum or CSF procalcitonin ${ }^{25}$ and serum C-reactive protein ${ }^{26}$ have not yet replaced CSF glucose in the evaluation of meningitis and were not systematically available in our data set. We did not include carcinomatous meningitis in our analysis, but doing this could provide yet another interesting angle, as cancerous cells are known to be highly catabolic. Overall, the aim of our analyses was to describe the relationship between CSF variables, as opposed to building a predictive score for the diagnosis of microbial meningitis that should be the focus of a larger prospective study. The percentage of diagnoses should be considered as information on the data used here and not as a cross-sectional study on meningitis differential diagnosis.

The strengths of this study include a relatively large sample size as compared to previously published data that encompassed a wide variety of confirmed etiologies including more recently recognized entities in the aseptic category, such as meningitides related to immunologic disturbances. The baseline characteristics were fairly balanced aside from an overrepresentation of men in the microbial category that we could not explain, as there are no reports suggesting a sex difference in this disease. As planned, the microbial category encompassed cases with a history of neurosurgery that may have had an impact on the blood-brain barrier permeability and thus bias glucose measurements. However, we feel that this is part of the variability of the clinical setting and serves to increase the generalizability of our findings. Indeed, repeating the analysis excluding cases with a history of neurosurgery yielded the same results (supplemental data, http:// links.lww.com/NXI/A3).

In conclusion, the data presented here shed light on meningitis pathophysiology by suggesting that the presence of a pathogen and the induced changes in CSF milieu, rather than inflammation alone, underlie hypoglycorrhachia. The practical correlate is that aseptic meningitis, even with a high level of leukocytes, should remain a diagnosis of exclusion if low-especially very low $(<30 \mathrm{mg} / \mathrm{dL})$-CSF glucose is present. Our data also support trending CSF glucose as a marker of treatment response and suggest that CSF glucose alone is a relatively specific marker of microbial meningitis, although the CSFto-serum ratio may be better in borderline cases. The early assessment of CSF glucose remains a vital component of the workup when a patient presents with signs of meningitis, as it can help distinguish between microbial meningitis requiring antimicrobial therapy and aseptic cases requiring very different treatment.

\section{AUTHOR CONTRIBUTIONS}

M.O.B., J.R.V., N.M.R., S.A.J., J.M.G., and S.M. conceptualized and designed the study; M.O.B., J.R.V., R.W., N.M.R., M.R.W., F.C.C., J.M.G., and S.M. acquired the data; M.O.B. and N.M.R. analyzed the data, including statistical analysis; and M.O.B., J.R.V., N.M.R., and R.W. drafted the manuscript and figures.

\section{STUDY FUNDING}

No targeted funding reported.

\section{DISCLOSURE}

M.O. Baud has a part-time appointment at the Wyss Center for Neurotechnologies and practices lumbar punctures at Geneva University Hospital. J.R. Vitt reports no disclosures. N.M. Robbins receives publishing royalties from the Oxford University Press and received research support from the Department of State Fulbright, the Hitchcock Foundation, and the Diamond Fund. R. Wabl reports no disclosures. M.R. Wilson received research support from the NIH/Natl Ctr Advancing Translational Science, Clinical and Translational Science Institute and the American Brain Foundation. F.C. Chow received research support from the NIH/NCATS. J.M. Gelfand served on the scientific advisory board for Genentech; consulted for Genentech; received research support to the UCSF from Quest Diagnostics; and received research support from the NIH; his wife served on a scientific advisory board for Eli Lilly, is Viewpoints editor of JAMA Neurology, consulted for Zosano, Biohaven, and Eli Lilly, and received research support to the UCSF from eNeura and Allergan. S.A. Josephson is editor-in-chief of JAMA Neurology, associate editor of The Neurohospitalist, Editor-in-Chief of Journal Watch Neurology, and associate editor of Continuum Online Edition. S. Miller served on the scientific advisory board for Luminex; receives publishing royalties form McGraw Hill; and received research support from Luminex, Altona Diagnostics, California Initiative to Advance Precision Medicine, the UCSF Clinical and Translational Sciences Institute, the Sandler Foundation, the Schwab Foundation, the Marcus Foundation, the Steven and Alexandra Cohen Foundation, and the Cystic Fibrosis Foundation. Go to Neurology.org/nn for full disclosure forms.

Received June 30, 2017. Accepted in final form October 3, 2017.

\section{REFERENCES}

1. Fishman RA. Cerebrospinal Fluid in Diseases of the Nervous System. 2nd ed. Philadelphia, PA: W.B. Saunders; 1992.

2. Weichsel M, Herzger G. Significance of the diminution of the spinal fluid sugar in tuberculous meningitis. J Pediatr 1936;9:763-770.

3. van de Beek D, de Gans J, Spanjaard L, Weisfelt M, Reitsma JB, Vermeulen M. Clinical features and prognostic factors in adults with bacterial meningitis. $\mathrm{N}$ Engl J Med 2004;351:1849-1859.

4. Silver TS, Todd JK. Hypoglycorrhachia in pediatric patients. Pediatrics 1976;58:67-71.

5. Gowin E, Wysocki J, Avonts D, Januszkiewicz-Lewandowska D, Michalak M. Usefulness of inflammatory biomarkers in discriminating between bacterial and aseptic meningitis in hospitalized children from a population with low vaccination coverage. Arch Med Sci 2016;2:408-414.

6. Dzupova O, Rozsypal H, Prochazka B, Benes J. Acute bacterial meningitis in adults: predictors of outcome. Scand J Infect Dis 2009;41:348-354.

7. Khoury NT, Hossain MM, Wootton SH, Salazar L, Hasbun R. Meningitis with a negative cerebrospinal fluid gram stain in adults: risk classification for an adverse clinical outcome. Mayo Clin Proc 2012;87:1181-1188.

8. Neuberger A, Shofty B, Bishop B, et al. Risk factors associated with death or neurological deterioration among patients with Gram-negative postneurosurgical meningitis. Clin Microbiol Infect 2016;22:573.e1-573.e4. 
9. Wee LYJ, Tanugroho RR, Thoon KC, et al. A 15-year retrospective analysis of prognostic factors in childhood bacterial meningitis. Acta Paediatr 2015;105:e22-e29.

10. Chow E, Troy SB. The differential diagnosis of hypoglycorrhachia in adult patients. Am J Med Sci 2014;348: 186-190.

11. Wengert O, Rothenfusser-Korber E, Vollrath B, et al. Neurosarcoidosis: correlation of cerebrospinal fluid findings with diffuse leptomeningeal gadolinium enhancement on MRI and clinical disease activity. J Neurol Sci 2013; 335:124-130.

12. Durel C-A, Marignier R, Maucort-Boulch D, et al. Clinical features and prognostic factors of spinal cord sarcoidosis: a multicenter observational study of 20 BIOPSY-PROVEN patients. J Neurol 2016;263:981-990.

13. Pavlidis N. The diagnostic and therapeutic management of leptomeningeal carcinomatosis. Ann Oncol 2004;15(suppl 4):iv285-iv291.

14. Tunkel AR, Hartman BJ, Kaplan SL, et al. Practice guidelines for the management of bacterial meningitis. Clin Infect Dis 2004;39:1267-1284.

15. Shrikanth V, Salazar L, Khoury N, Wootton S, Hasbun R. Hypoglycorrhachia in adults with community-acquired meningitis: etiologies and prognostic significance. Int J Infect Dis 2015;39:39-43.

16. Menkes JH. The causes for low spinal fluid sugar in bacterial meningitis: another look. Pediatrics 1969;44:1-3.

17. Petersdorf RG, Harter DH. The fall in cerebrospinal fluid sugar in meningitis: some experimental observations. Arch Neurol 1961;4:21-30.
18. Hochwald GM, Nakamura S, Chase R, Gorelick J. Cerebrospinal fluid glucose and leukocyte responses in experimental meningitis. J Neurol Sci 1984;63:381-391.

19. Bretz G, Mauer AM. Glucose consumption by polymorphonuclear leukocytes in the cerebrospinal fluid of patients with bacterial meningitis. J Pediatr 1967;70:767-771.

20. Flanagan EP, Kaufmann TJ, Krecke KN, et al. Discriminating long myelitis of neuromyelitis optica from sarcoidosis. Ann Neurol 2016;79:437-447.

21. Sarva H, Chapman R, Omoregie E, Abrams C. The challenge of profound hypoglycorrhachia: two cases of sarcoidosis and review of the literature. Clin Rheumatol 2011;30:1631-1639.

22. Koth LL, Solberg OD, Peng JC, Bhakta NR, Nguyen CP, Woodruff PG. Sarcoidosis blood transcriptome reflects lung inflammation and overlaps with tuberculosis. Am J Respir Crit Care Med 2011;184:1153-1163.

23. Nigrovic LE, Kimia AA, Shah SS, Neuman MI. Relationship between cerebrospinal fluid glucose and serum glucose. N Engl J Med 2012;366:576-578.

24. Powers WJ. Cerebrospinal fluid to serum glucose ratios in diabetes mellitus and bacterial meningitis. Am J Med 1981;71:217-220.

25. Wei TT, Hu ZD, Qin BD, et al. Diagnostic accuracy of procalcitonin in bacterial meningitis versus nonbacterial meningitis: a systematic review and meta-analysis. Medicine 2016;95:e3079.

26. Ray P, Badarou-Acossi G, Viallon A, et al. Accuracy of the cerebrospinal fluid results to differentiate bacterial from non bacterial meningitis, in case of negative gram-stained smear. Am J Emerg Med 2007;25:179-184. 


\section{Neurology ${ }^{\oplus}$ \\ Neuroimmunology \& Neuroinflammation}

Pleocytosis is not fully responsible for low CSF glucose in meningitis

Maxime O. Baud, Jeffrey R. Vitt, Nathaniel M. Robbins, et al.

Neurol Neuroimmunol Neuroinflamm 2018;5;

DOI 10.1212/NXI.0000000000000425

This information is current as of December 26, 2017

Neurol Neuroimmunol Neuroinflamm is an official journal of the American Academy of Neurology.

Published since April 2014, it is an open-access, online-only, continuous publication journal. Copyright

Copyright $\odot 2017$ The Author(s). Published by Wolters Kluwer Health, Inc. on behalf of the American

Academy of Neurology. All rights reserved. Online ISSN: 2332-7812.

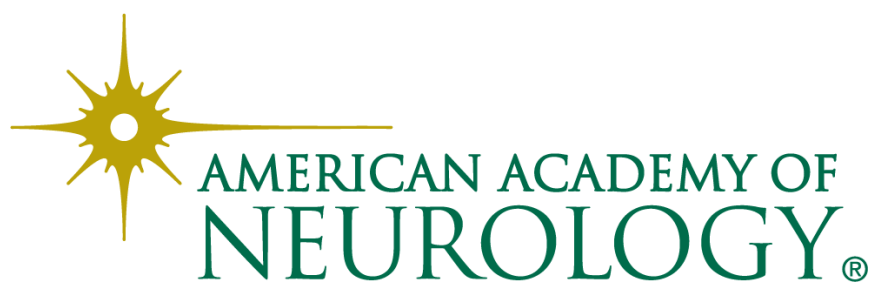




\section{Updated Information \& Services}

\section{Supplementary Material}

\section{References}

Citations

Subspecialty Collections

Permissions \& Licensing

Reprints including high resolution figures, can be found at: http://nn.neurology.org/content/5/1/e425.full.html

Supplementary material can be found at: http://nn.neurology.org/content/suppl/2017/12/26/5.1.e425.DC1

This article cites 25 articles, 0 of which you can access for free at: http://nn.neurology.org/content/5/1/e425.full.html\#\#ref-list-1

This article has been cited by 2 HighWire-hosted articles: http://nn.neurology.org/content/5/1/e425.full.html\#\#otherarticles

This article, along with others on similar topics, appears in the following collection(s):

\section{All Immunology}

http://nn.neurology.org//cgi/collection/all_immunology

\section{All Infections}

http://nn.neurology.org//cgi/collection/all_infections

Meningitis

http://nn.neurology.org//cgi/collection/meningitis

Information about reproducing this article in parts (figures,tables) or in its entirety can be found online at:

http://nn.neurology.org/misc/about.xhtml\#permissions

Information about ordering reprints can be found online: http://nn.neurology.org/misc/addir.xhtml\#reprintsus

Neurol Neuroimmunol Neuroinflamm is an official journal of the American Academy of Neurology.

Published since April 2014, it is an open-access, online-only, continuous publication journal. Copyright

Copyright $\odot 2017$ The Author(s). Published by Wolters Kluwer Health, Inc. on behalf of the American Academy of Neurology. All rights reserved. Online ISSN: 2332-7812.

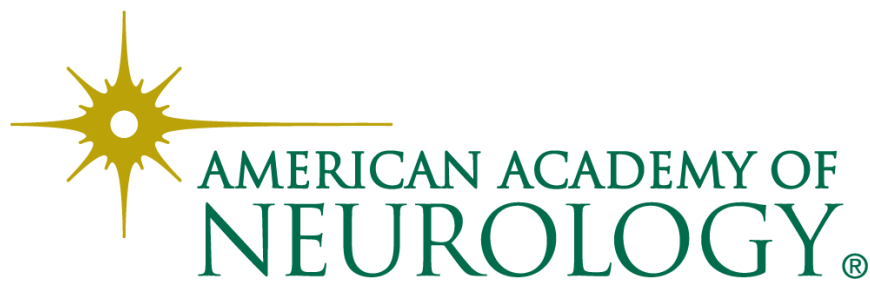

